\title{
Fabrication and Mechanical Characterization of Jute-Coir Reinforced Unsaturated Polyester Resin Hybrid Composites with Various Fiber Size using Compression Moulding Technique
}

\author{
D. Sarukasan, K. Thirumavalavan, Prahadeeswaran M, R. Muruganandhan
}

\begin{abstract}
Fiber reinforced composites plays major role in improving the strength of various applications in current trends. Based on these trends the combination of natural jute/coir fiber hybrid composite of different size of fiber length was examined in this study. The hybrid fiber composite was fabricated by compression moulding technique by impregnating jute fiber and coir fiber with unsaturated polyester resin, Cobalt octoate and methyl-ethyl-ketone peroxide as accelerator and catalyst. Then the prepared mould placed into the oven to dry for 4 hrs. at $50^{\circ} \mathrm{C}$ beneath closely to vacuum condition then convert the cured mould to the hot press initially for $1 \mathrm{hr}$ at $105^{\circ} \mathrm{C}$ under 84 bar pressure until while squeeze out the excess resin, then it was cooled in cold press under constant pressure of 275 bar pressure for $15 \mathrm{~min}$ to prevent the warpage of hybrid composites. The micro hardness, tensile, flexural, impact strength of hybrid composite was carried out and the morphology of the composites was evaluated and compared. The test results of the hybrid composite were analyzed by one way ANOVA analysis technique and it shows significant difference among the groups.
\end{abstract}

Keywords: Hybrid Composite, Compression Moulding Technique, Mechanical Properties, Scanning Electron Microscope, Statistical Analysis

\section{INTRODUCTION}

The uses of composites over straight materials are highly due to their stiffness, fatigue strength and durability which enhance the structure more compact. By statement, composite comprises of two or more elements which combines of both physical and chemical phases.

Manuscript received on May 19, 2021

Revised Manuscript received on May 22, 2021.

Manuscript published on May 30, 2021.

* Correspondence Author

Mr. D. Sarukasan*, Research Scholar, Department of Mechanical Engineering, College of Engineering Guindy, Anna University, Chennai, Tamil Nadu, India.

Dr. K. Thirumavalavan, Assistant Professor, Department of Mechanical Engineering, College of Engineering Guindy, Anna University, Chennai, Tamil Nadu, India.

Mr. Prahadeeswaran M, Research Scholar, Department of Industrial Engineering, College of Engineering Guindy, Anna University, Chennai, Tamil Nadu, India.

Dr. R.Muruganandhan, Associate Professor, Department of Mechanical Engineering, College of Engineering, Guindy, Anna University, Chennai, Tamil Nadu, India.

(C) The Authors. Published by Blue Eyes Intelligence Engineering and Sciences Publication (BEIESP). This is an open access article under the CC BY-NC-ND license (http://creativecommons.org/licenses/by-nc-nd/4.0/)
The reinforcement materials incorporated in base matrix helps in increasing strength and rigidity. It may be particles, fibres or platelets are economically used to improve the mechanical strength which offers effective load transfer [1, 2]. Among different types of reinforced composites natural fibre reinforced polymer composites were commonly used due to its availability, low density, cost and improved energy recovery [3,4]. Since natural fibre are classified as jute, banana, coconut, palm fibres, etc. Increased mechanical property simultaneously increases the fibre weight index which reduces the tensile strength [5].

In this work coir and jute fibres are used as raw material for its non-hazardous, lignin ratio and less wear. Kumar et al. [6] states that coir fibre reinforced polymer composites increases the mechanical strength of the composite due to reinforcements and higher addition of coir fibres breaks the interfacial bonding between the fibres and weakens the composite. Fernanda et al. [7] observed that epoxy reinforced composites at different wt. \% of 10, 20 and 30 forms an multi-layer protective system which $0.2 \%$ lighter and $34 \%$ cheaper than other composites. Gireesan et al. [8] conclude that the coir epoxy reinforced composite fabricated through hand layup process increases the hardness and tensile where higher addition of fibre debilitates the structure. Sivasaravanan et al. [9] states that nanocomposites prepared by hand layup method has superior mechanical properties where the addition of epoxy/clay reinforcements at $5 \mathrm{wt}$. \% has good mechanical property. Obele and Ishidi [10] reports coir fibre reinforced at $30 \mathrm{wt}$. \% has stable mechanical property with reduced weight. The epoxy reinforced polymer composite exhibit high impact and compressive strength with 30 wt. \% of coir fibre where the higher addition of coir fibre reduces the composite strength. Pani and Mishra [11] conclude that coir reinforced with epoxy matrix at $10 \mathrm{wt}$ \% has increased mechanical properties with the effect of mercerization when compared with treated and untreated fibres. Singh et al. [12] states that alkali treated coir fibre reinforced epoxy composite has superior mechanical properties than untreated fibre. It concludes that fibre reinforced at $30 \mathrm{wt}$. \% has better impact, compressive and flexural properties and due to alkali behaviour reduces the moisture content.

Published By:

Blue Eyes Intelligence Engineering and Sciences Publication

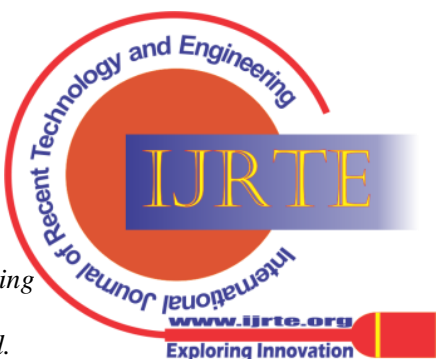


Vinayaka and Yohannes [13] relates that increasing the nano clay wt. \% decrease the tensile strength due to wettability while matrix content gets reduced. The bonding strength increases from 0 to 1 wt. \% and decreases at 5 and 7 wt. \% due to discontinuous fibres. Kumar et al.

[14] concludes carbon/epoxy composite has enhanced mechanical strength than the epoxy reinforced with glass and hybrid composite it's due to low bending strength and stiffed reinforcements which reduces the flexural, compressive and impact strength of composites. Adeniyi et al. [15] states that fibre surface modification treatment increase the interfacial adhesion thereby increasing the physical and chemical properties of the coir fibre reinforced polymer composites. Santos et al. [16] observed that due to fibre matrix adhesion the alkali treated composites does not sensitively changes the fibre surface instead it enhance the mechanical strength of the composite when treatment time is increased to 96 or 168 hours. Yan et al. [17] concludes the alkali treated coir fibre with 5 wt. \% of $\mathrm{NaOH}$ exhibit clear and rougher surface where the untreated reveals the fibre debonding and film breakage. Yan and Chouw [18] states at different ageing conditions composite immersed in $\mathrm{NaOH}$ solution which slightly reduce the degradation of fibre/matrix bond which is highly depends on immersion temperature and matrix used. Ali and Chouw [19] results that when compared to soaked treatment the tensile and elongation of the fibre is increased by boiling treatment and decreased by alkali treatment where the bond strength is reduced by $11 \%$ and pull out energy decreases by $44 \%$ with increased length from 100 to $200 \mathrm{~nm}$. Stephano [20] concludes that coconut coir epoxy and hardener reinforced hybrid composite prepared by hand layup technique were very economical, biodegradable with increased mechanical properties.

Literature survey reveals the advantages of research work in fabrication of coir fiber and jute fiber hybrid reinforced epoxy based composites. The evaluation of mechanical strength of composites like tensile, compressive, flexural, etc. studied by mechanical testing. The statistical analysis of hybrid composites is studied using One-way ANOVA Analysis and the fracture failures are studied using Scanning Electron Microscope (SEM).

\section{MATERIALS AND METHODS}

\section{A. Materials}

Jute fiber mat and coir fiber mat was acquired from Indarsen Shamlal Private Limited, Kolkata, India and D.C. Mills Private Limited Alleppey, India. Unsaturated polyester resin for general purpose manufactured by Kanoria chembond Private Limited was purchased from Mumbai, Cobalt octoate and methyl-ethyl-ketone peroxide as accelerator and catalyst manufactured by Triveni Interchem Private Limited was were purchased from Mumbai. Sodium hydroxide pallets were supplied by Emplura, Merck Life Science Private Limited with molarity of $40.0 \mathrm{~g} / \mathrm{mol}$. Benzyl alcohol used as diluents and silicone oil used as releasing agent for the fabrication of hybrid composite which supplied by Aldrich Company. [21,22] The physical and mechanical properties of coir and jute fiber are given in Table 1 along with that fiber image was
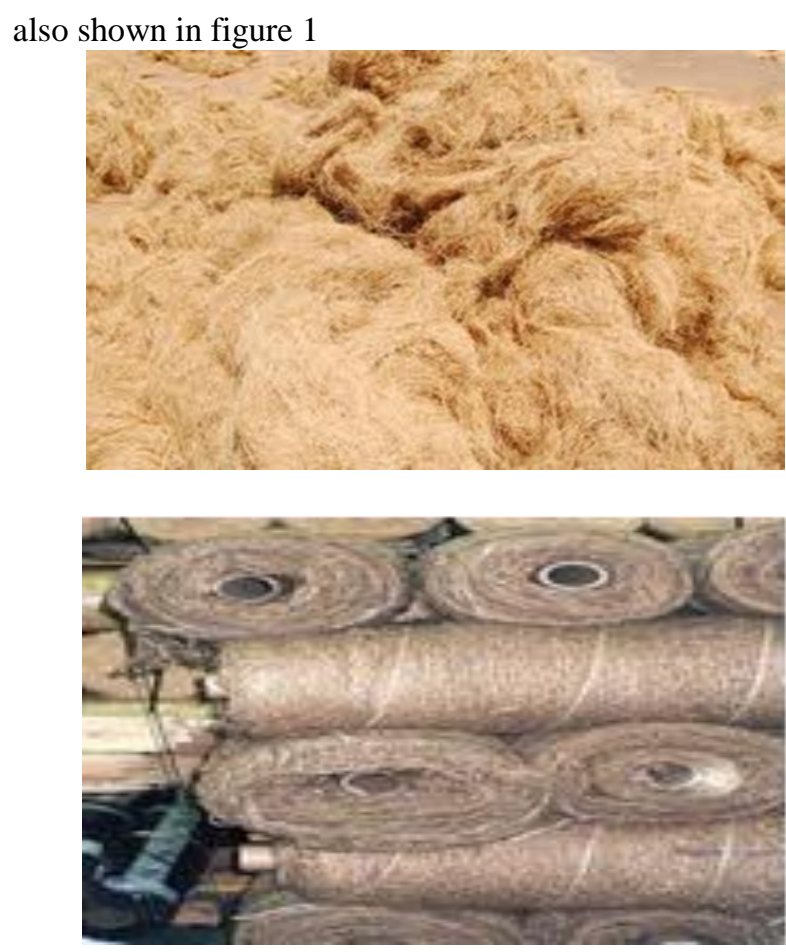

Figure 1 Coir fiber and jute fiber

\begin{tabular}{|c|l|c|c|}
\hline S.No. & \multicolumn{1}{|c|}{ Properties } & Coir fiber & Jute fiber \\
\hline 1. & Density (g/cm3 ) & 1.4 & 1.3 \\
\hline 2. & Tensile strength (MPa) & $175-240$ & $39-773$ \\
\hline 3. & Young's modulus (GPa) & 30 & $10-30$ \\
\hline 4. & Elongation at break (\%) & $15-17$ & $1.5-1.8$ \\
\hline 5. & Cellulose content (\%) & 43.44 & $58-63$ \\
\hline 6. & Hemicellulose (\%) & 0.25 & 12 \\
\hline 7. & Lignin content (\%) & 45.84 & $12-14$ \\
\hline 8. & Microfibril angle ( $\left.{ }^{\circ}\right)$ & $30-48$ & 8 \\
\hline 9. & Lumen size (mm) & 12 & 3.40 \\
\hline
\end{tabular}

Table 1 Physical and Mechanical Properties of jute fiber and coir fiber

\section{B. Enrichment Treatment Of Coir Fiber And Jute Fiber}

The accumulated coir fiber and jute fiber was first splashed through normal tap water to remove the dust, dirt, mud and other adhered particles on the fiber surface. The coir fiber are then soaked in hot water at $70^{\circ} \mathrm{C}$ for $2 \mathrm{~h}$, then rinsed with deionized water. Later the fiber were mercerized with $5 \%$ $\mathrm{NaOH}$ solution for 4 hours at room temperature with complete dissolving of fiber ratio of 20:1. The treated fiber were washed several times with deionized water to remove $\mathrm{NaOH}$ sticking on the fiber surface until a final $\mathrm{pH}$ of 7 was conquered. To neutralize the alkali dilute acetic acid was used. The fiber were then dried at room temperature for 48 hours followed by oven drying at $100^{\circ} \mathrm{C}$ for 6 hours. These fibers were preserved in a conditioned room at $25^{\circ} \mathrm{C}$ and humidity of $50 \%$ for future studies.[23] The mercerization of natural fiber occurs according to equation (1)

\section{Published By:}

Blue Eyes Intelligence Engineering

and Sciences Publication

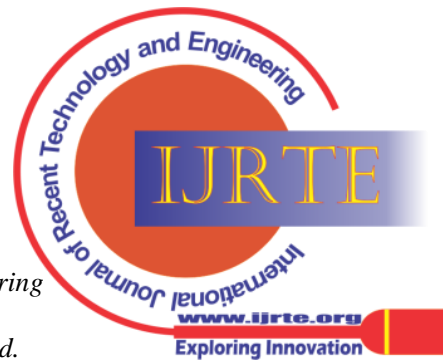


Fiber $-\mathrm{OH}+\mathrm{NaOH} \rightarrow$ Fiber $-\mathrm{O}--\mathrm{Na}^{+}+\mathrm{H} 20 \ldots$ Eqn. (1)

\section{Fabrication of Hybrid Composite}

Initially for preparation of the hybrid composite, a wooden mould with dimensions 304mm X 203mm X 4 mm were prepared and fixed over the cardboard using iron nails. The mould was coated with a thin layer of silicone oil solution, acts as a releasing agent. The preparation of matrix for hybrid composites were unsaturated polyester resin with Cobalt octoate and methyl-ethyl-ketone peroxide as accelerator and catalyst with 100:60 ratio were mixed and benzyl alcohol was added as diluents and the mixture was mixed thoroughly by mechanical stirrer for $20 \mathrm{~min}$.[24] The coir fiber mat and jute fiber mat are cut into $10 \mathrm{~mm}, 20 \mathrm{~mm}, 30 \mathrm{~mm}$ length for different sizes for hybrid composite component. The processing flow of the compression moulding technique was noticed in figure 2.

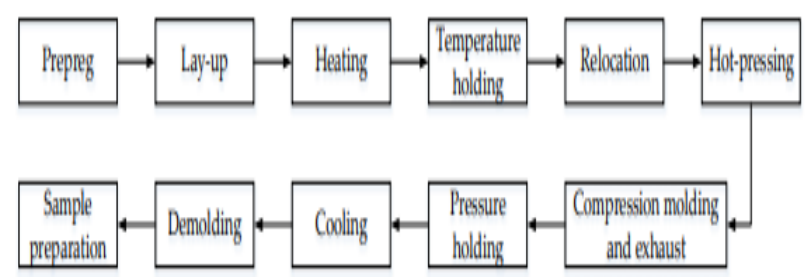

Figure 2 Processing flow chart of compression moulding technique

The different sizes of hybrid composite were developed using compression moulding technique for making the test specimen. Keeping the different weight ratio of reinforcement of total fiber $40 \%$ by weight, bilayer hybrid composites were prepared by hybridizing of unsaturated polyester resin and both jute fiber and coir fiber mats were impregnated in mould. The unsaturated polyester resin was poured over the fiber evenly then pressed and pushed down with stainless steel roller to avoid and eliminate the air bubbles until the filling of mould was complete. Then place the prepreg mould into oven to dry for 4 hrs at $50^{\circ} \mathrm{C}$ beneath closely to vacuum condition then convert the cured mould to the hot press initially for $1 \mathrm{hr}$ at $105^{\circ} \mathrm{C}$ under 84 bar pressure until while squeeze out the excess resin, then it were cooled in cold press under constant pressure of 275 bar pressure for 15 min to prevent the

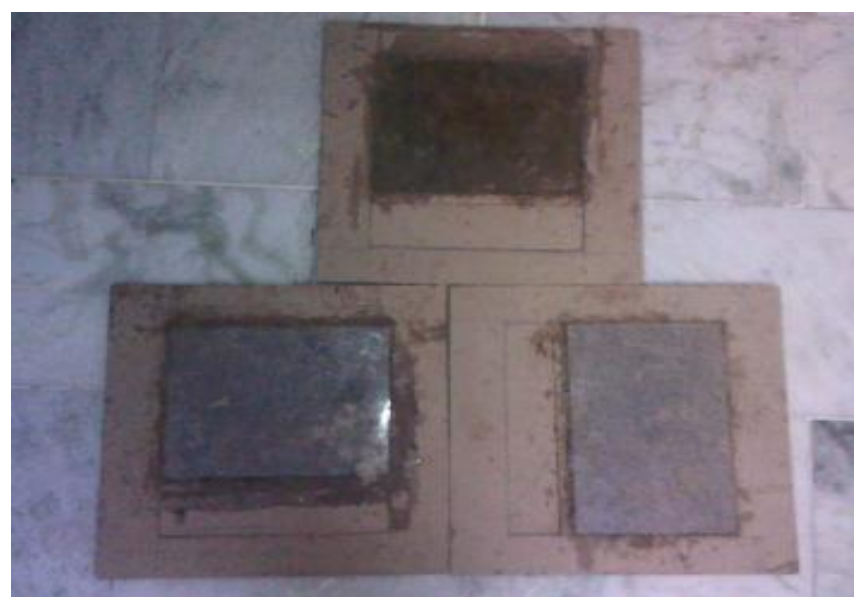

Figure 3 Compression moulding technique of hybrid composite specimen warpage of hybrid composites.

\section{Characterization of Hybrid Composites}

\section{Tensile test}

Tensile test of different size of hybrid composite samples in wrap and wrap direction was taken in Instron Universal testing machine (maximum test force: $50 \mathrm{~N} \sim 10 \mathrm{kN}$; effective space of tension: $700 \mathrm{~mm}$; effective test width: 300 $\mathrm{mm}$ ) according to the ASTM D3039 test standard, each tensile test sample was prepared with a width of $25 \mathrm{~mm}$ and a total length of $250 \mathrm{~mm}$ and subjected to tensile loading at 2 $\mathrm{mm} / \mathrm{min}$ with the standard strain rate of $0.01 \mathrm{~min}-1 .[25,33]$

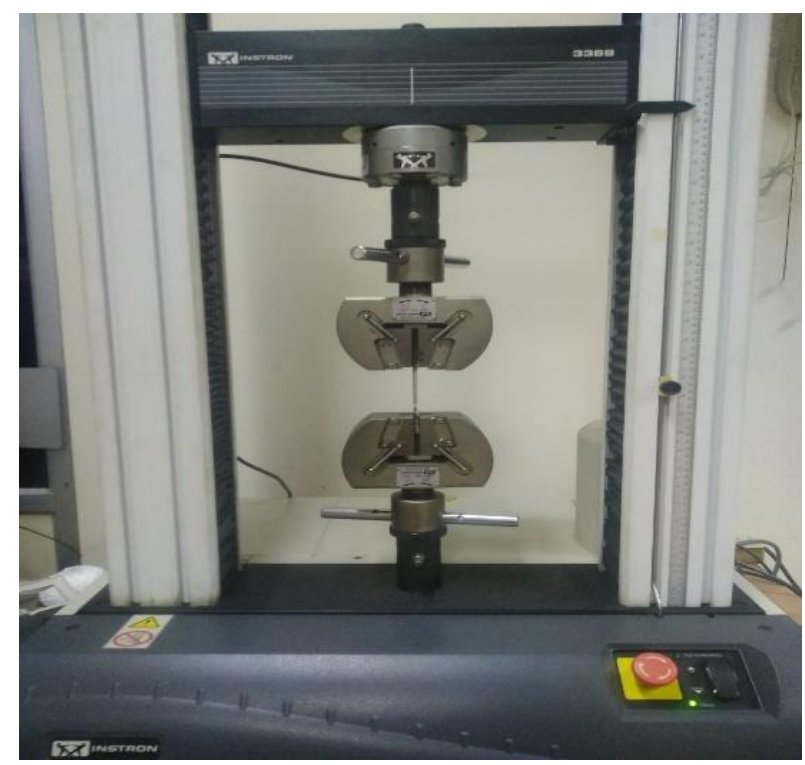

Figure 4 Universal Tensile Test Machine

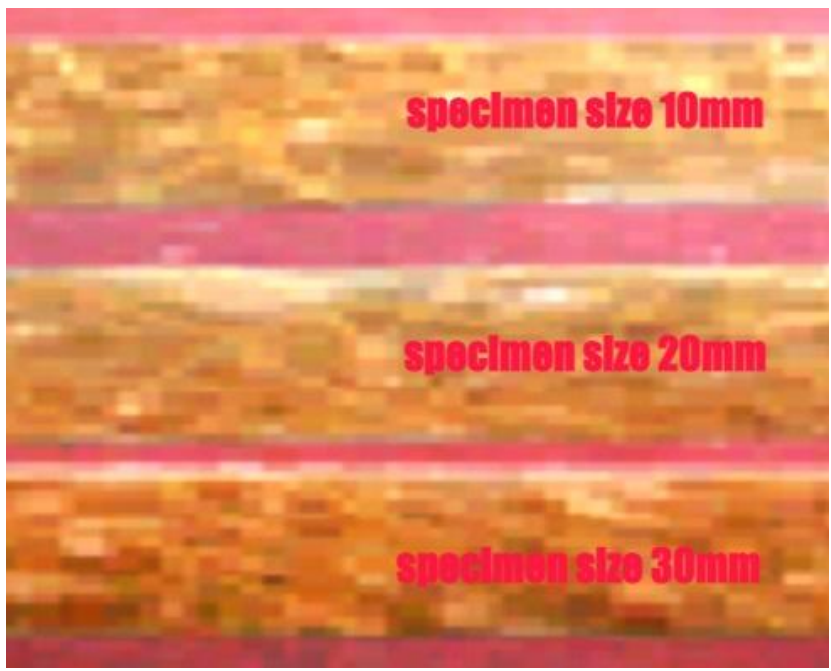

Figure 5 Tensile Test specimens

\section{Flexural Test}

Flexural analysis of different size of hybrid composite specimen with rectangular dimensions of ASTM D790 standard using Gotech universal tester-GT-A1-7000L machine shown in figure 6 . The rectangular samples of dimension 160 X $20 \mathrm{~mm} 2$ were cut using circular saw as shown in figure 7 . The speed of the crosshead was $2 \mathrm{~mm} / \mathrm{min}$. Two composite specimens were tested for each sample.[26]

Published By:

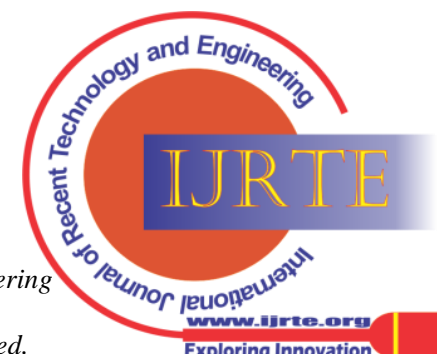


Fabrication and Mechanical Characterization of Jute-Coir Reinforced Unsaturated Polyester Resin Hybrid Composites with Various Fiber Size using Compression Moulding Technique

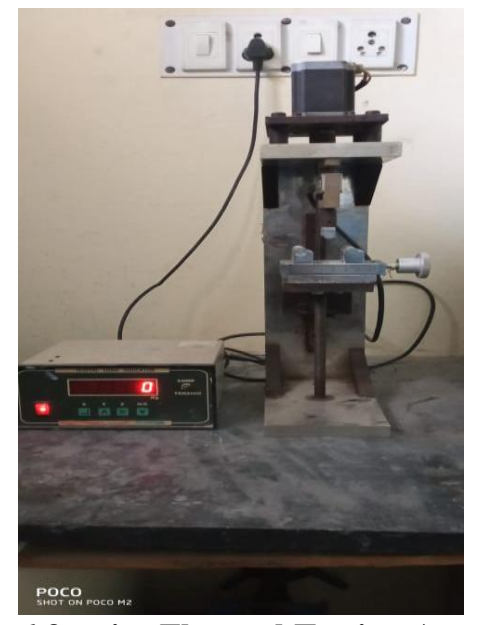

Figure 6 3-point Flexural Testing Apparatus

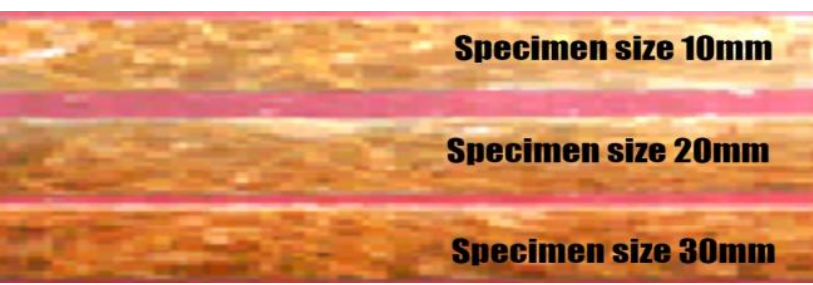

Figure 7 Flexural Test specimens

\section{Micro Hardness Test}

The hardness test was carried out using Vickers micro hardness analyser at material testing lab as shown in figure 8 with indenter of pyramid shape at edge $136^{\circ}$ and test load utilized for different size hybrid fiber composites specimen were $2.942\{\mathrm{HV} 0.3\}$, in accordance to ASTM E-384 standard. The hardness test was conducted for two specimens, for each specimen three measurements point were recorded then the average value are suggested.[27]

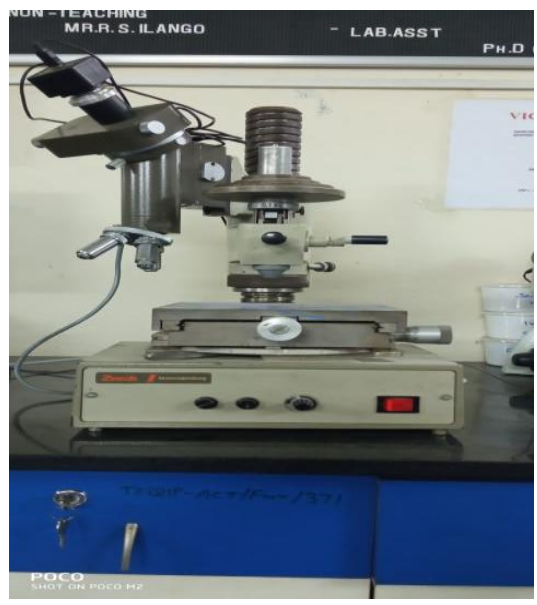

Figure 8 Micro-Hardness testing Apparatus

\section{Impact Test}

In this study, Izod notched impact testing was carried out using Go-tech testing machine, Model GT-7045-MDL. The Izod impact test samples with a dimension of $70 \mathrm{X} 15 \mathrm{~mm} 2$ were cut by jig saw. According to ASTM D256 standard their average load at first deformation was noticed and average value are tabulated as impact strength.[28]

\section{Fractography Analysis using SEM}

The hybrid fiber composite microstructure was investigated using a scanning electron microscope model FEI
Quanta 400 located in material characterization lab at Anna University. Initially the specimen was coated with approximately $20 \mathrm{~nm}$ of gold to become more conductive and suitable for SE analysis. The SEM was operated using $25 \mathrm{kV}$ of acceleration tension and $30 \mathrm{~mm}$ of working distance. The images were attained using the software package ImageJ for measuring fractography of the tensile tested specimens.[29]

\section{Statistical Analysis}

Statistical analysis has been taken out using one-way analysis of variance (ANOVA) with two different parameters and the results are discussed. The statistical analysis of difference between the specimen regarding flexural strength and tensile strength are examined respectively.[30]

\section{RESULT AND DISCUSSION}

\section{A. Tensile Properties}

The mechanical properties results exhibited the effect of $\mathrm{NaOH}$ treated with different size of 2coir and jute fiber hybrid composites. It is clearly evident that the length of coir and jute fiber of 10,20,30 $\mathrm{mm}$ with unsaturated polyester resin significantly affected the tensile strength of hybrid composites. The enriched chemical treatment of fabricating hybrid fiber composite gives more strength along with matrix binding. The tensile strength is perceiving to increase with increasing in size of coir and jute fiber up to $20 \mathrm{~mm}$ and fiber weight fraction of $40 \%$ beyond which it starts decreasing. Proper reinforcement and matrix bonding of hybrid composites with increasing size might give decreasing strength of tensile properties. The table 2 delivers that tensile test was taken for two specimen of same size and the average value is noticed. It is noticed that $20 \mathrm{~mm}$ size of hybrid fiber composites has maximum tensile strength of 23 Mpa which shows high improvement of $1 \%$ and $23 \%$ of $10 \mathrm{~mm}$ and $30 \mathrm{~mm}$ than other fiber size hybrid composites as shown in figure 9.

Table 2 Tensile properties of jute/coir fiber hybrid composites

\begin{tabular}{|c|c|c|c|c|}
\hline S.NO & $\begin{array}{c}\text { FIBER } \\
\text { (Length } \\
\text { mm) } \\
40 \% \\
\text { (JF+CF) }\end{array}$ & SPECIMENS & $\begin{array}{c}\text { TENSILE } \\
\text { STRENGTH } \\
\text { (Mpa) }\end{array}$ & $\begin{array}{c}\text { AVERAGE } \\
\text { TENSILE } \\
\text { STRENGTH } \\
\text { (Mpa) }\end{array}$ \\
\hline \multirow{3}{*}{1} & \multirow{3}{*}{10} & $\mathrm{~T}_{1}$ & 20 & \multirow{3}{*}{22.5} \\
\hline & & $\mathrm{T}_{12}$ & 22 & \\
\hline & & $\mathrm{T}_{13}$ & 25 & \\
\hline \multirow{3}{*}{2} & \multirow{3}{*}{20} & $\mathrm{~T}_{21}$ & 21 & \multirow{3}{*}{23} \\
\hline & & $\mathrm{T}_{22}$ & 23 & \\
\hline & & $\mathrm{T}_{23}$ & 25 & \\
\hline \multirow{3}{*}{3} & \multirow{3}{*}{30} & $\mathrm{~T}_{31}$ & 13 & \multirow{3}{*}{15} \\
\hline & & $\mathrm{T}_{32}$ & 14 & \\
\hline & & $\mathrm{T}_{33}$ & 16 & \\
\hline
\end{tabular}

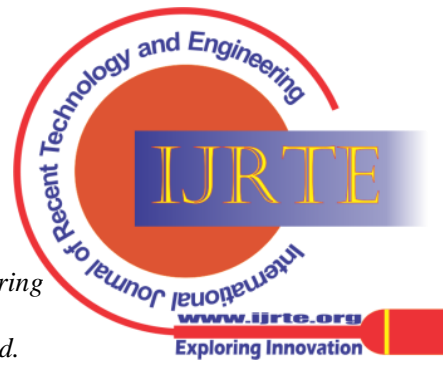




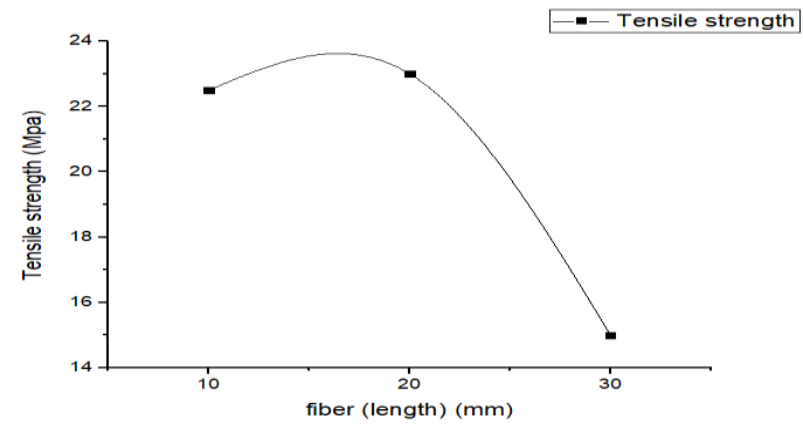

Figure 9 Tensile strength of hybrid composites

\section{B. Flexural Properties}

The flexural properties were measured for specimens of each fiber hybrid composites of different size with the help of the flexural stress/strain curves and respective equations. The effect of fiber loading on flexural strength of the hybrid composites having weight fraction and variation of the flexural strength for different size of coir and jute reinforced hybrid composites is shown in table 3. The flexural load was applied in 3-point bending apparatus on the hybrid fiber composites that when bending took place, the coir fiber has higher strength compared to jute fiber which withstand higher stress during flexural testing. It is noticed that $20 \mathrm{~mm}$ size of hybrid fiber composites has maximum flexural strength of 57.25 Mpa which shows high improvement of $10.6 \%$ and $32.41 \%$ of $10 \mathrm{~mm}$ and $30 \mathrm{~mm}$ than other fiber size hybrid composites as shown in figure 10 .

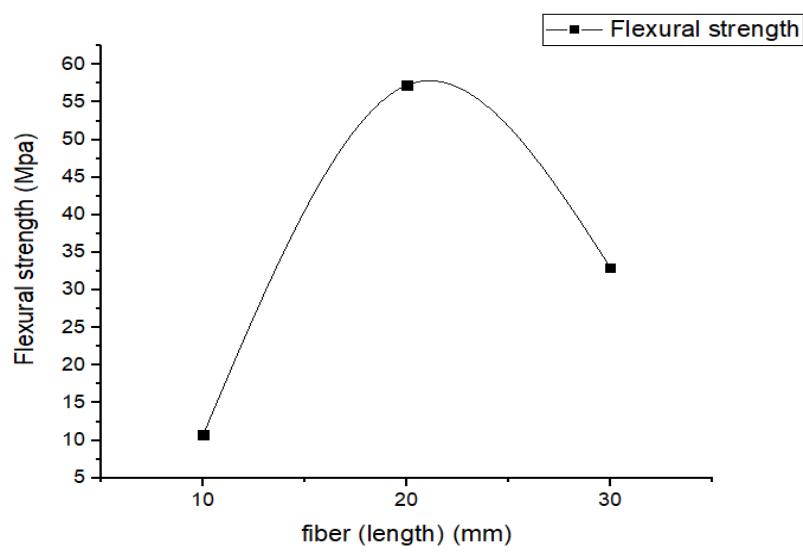

Figure 10 Flexural strength of hybrid composites

Table 3 Flexural properties of jute/coir fiber hybrid composites

\begin{tabular}{|c|c|c|c|c|}
\hline S.NO & $\begin{array}{c}\text { FIBER } \\
\text { (Length } \\
\text { mm) } \\
40 \% \\
(\mathrm{JF}+\mathrm{CF} \\
)\end{array}$ & $\begin{array}{c}\text { SPECIMEN } \\
\mathrm{S}\end{array}$ & $\begin{array}{c}\text { FLEXURAL } \\
\text { STRENGT } \\
\text { H } \\
\text { (Mpa) }\end{array}$ & $\begin{array}{c}\text { AVERAGE } \\
\text { FLEXURAL } \\
\text { STRENGT } \\
\text { H } \\
\text { (Mpa) }\end{array}$ \\
\hline \multirow{3}{*}{1} & \multirow{3}{*}{10} & $\mathrm{~F}_{11}$ & 9.2 & \multirow{3}{*}{10.8} \\
\hline & & $\mathrm{F}_{12}$ & 10.5 & \\
\hline & & $\mathrm{F}_{13}$ & 12.5 & \\
\hline \multirow{3}{*}{2} & \multirow{3}{*}{20} & $F_{21}$ & 52 & \multirow{3}{*}{57.25} \\
\hline & & $\mathrm{F}_{22}$ & 57 & \\
\hline & & $\mathrm{F}_{23}$ & 62.5 & \\
\hline \multirow{3}{*}{3} & \multirow{3}{*}{30} & $F_{31}$ & 25 & \multirow{3}{*}{33} \\
\hline & & $F_{32}$ & 34 & \\
\hline & & $\mathrm{F}_{33}$ & 38 & \\
\hline
\end{tabular}

\section{Impact Properties}

The impact strength values of different size coir and jute hybrid reinforced unsaturated polyester resin composite are given in the table 4 . It delivers that the resistance to impact loading of coir/jute fiber reinforcement which improves strength with increase in fiber length at certain level beyond that the strength will get decreases. Based on this the three different size of fiber length hybrid composites are choosen for impact test analysis. For each size of fiber length three same size specimen taken for test purposes and average value are taken. The average impact strength value of different fiber size are shown in figure 11 Among that the impact strength of $20 \mathrm{~mm}$ fiber size hybrid composite gives $15.3 \mathrm{~J}$ of most effective result with $12.8 \%$ and $9.6 \%$ high improvement than other combination.

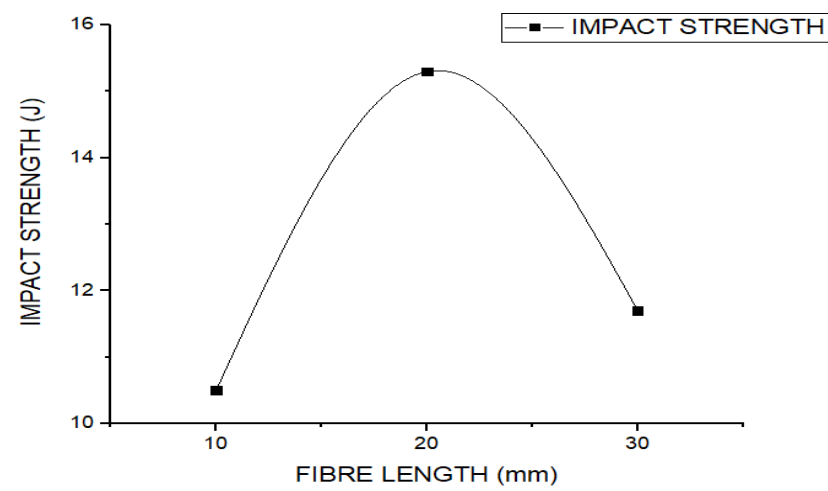

Figure 11 Impact strength of hybrid composites

Table 4 Impact Properties of jute/coir fiber hybrid composites

\begin{tabular}{|c|c|c|c|c|}
\hline $\begin{array}{c}\text { S.N } \\
\text { O }\end{array}$ & $\begin{array}{c}\text { FIBER } \\
\text { (Length } \\
\text { mm) } \\
40 \% \\
(\mathrm{JF}+\mathrm{CF})\end{array}$ & $\begin{array}{c}\text { SPECIMEN } \\
\mathrm{S}\end{array}$ & $\begin{array}{c}\text { IMPACT } \\
\text { STRENGT } \\
\text { H } \\
\text { (J) }\end{array}$ & $\begin{array}{c}\text { AVERAGE } \\
\text { IMPACT } \\
\text { STRENGT } \\
\text { H } \\
\text { (J) }\end{array}$ \\
\hline \multirow{3}{*}{1} & \multirow{3}{*}{10} & $\mathrm{I}_{11}$ & 8 & \multirow{3}{*}{10.5} \\
\hline & & $\mathrm{I}_{12}$ & 11 & \\
\hline & & $\mathrm{I}_{13}$ & 13 & \\
\hline \multirow{3}{*}{2} & \multirow{3}{*}{20} & $\mathrm{I}_{21}$ & 11 & \multirow{3}{*}{15.3} \\
\hline & & $I_{22}$ & 20 & \\
\hline & & $\mathrm{I}_{23}$ & 15 & \\
\hline \multirow{3}{*}{3} & \multirow{3}{*}{30} & $\mathrm{I}_{31}$ & 9 & \multirow{3}{*}{11.7} \\
\hline & & $\mathrm{I}_{32}$ & 14 & \\
\hline & & $\mathrm{I}_{33}$ & 12 & \\
\hline
\end{tabular}

\section{Hardness Properties}

According to the ASTM standard the hardness test was carried out for three specimens of different fiber length of jute/coir reinforced unsaturated polyester resin hybrid composites with five different locations on same specimens[31]. The values of entire specimens is calculated as average hardness value shown in table 5 . The result shows that the hardness value of $10 \mathrm{~mm}$ fiber length hybrid composite at the range of 38 to $44,20 \mathrm{~mm}$ fiber length hybrid composite at the range of 42 to 55 and $30 \mathrm{~mm}$ fiber length hybrid composite at the range of 35 to 44 as shown in figure 12 .

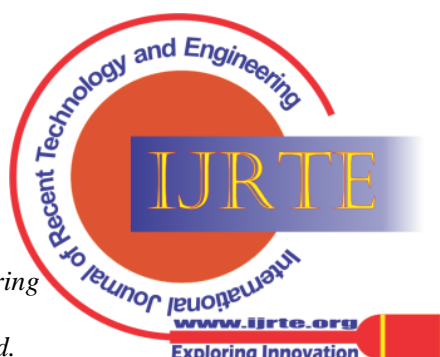


Fabrication and Mechanical Characterization of Jute-Coir Reinforced Unsaturated Polyester Resin Hybrid Composites with Various Fiber Size using Compression Moulding Technique

The average hardness value are shown in figure 13 and $10 \mathrm{~mm}$ fiber length hybrid composite has high improvement of $6.28 \%$ and $7.75 \%$ than other combinations.

\begin{tabular}{|c|c|c|c|c|c|c|c|c|}
\hline $\begin{array}{l}z_{1} \\
\dot{\omega}\end{array}$ & 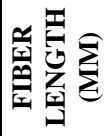 & 悬 & 胥 & $\stackrel{n}{B}$ & 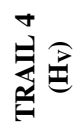 & 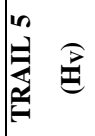 & 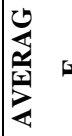 & $\widehat{E}$ \\
\hline 1 & 10 & 38 & 41 & 44 & 42 & 40 & & 11 \\
\hline 2 & 20 & 42 & 45 & 50 & 55 & 51 & & 49 \\
\hline 3 & 30 & 39 & 41 & 38 & 35 & 44 & & 39 \\
\hline
\end{tabular}

Table 5 Micro Hardness Value of jute/coir fiber hybrid composites

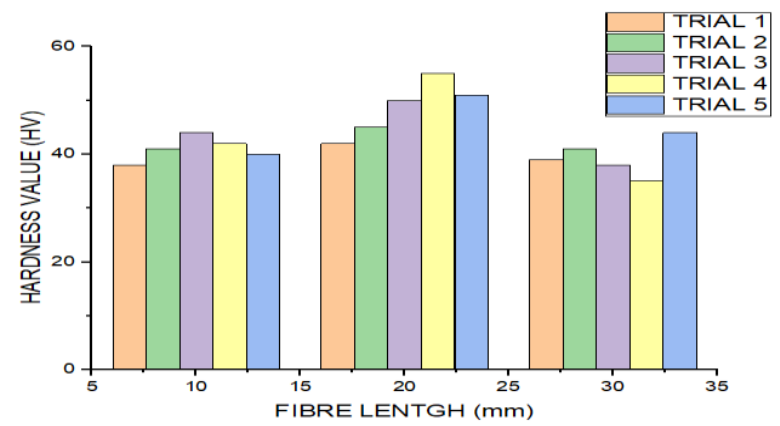

Figure 12 Hardness value of hybrid composites

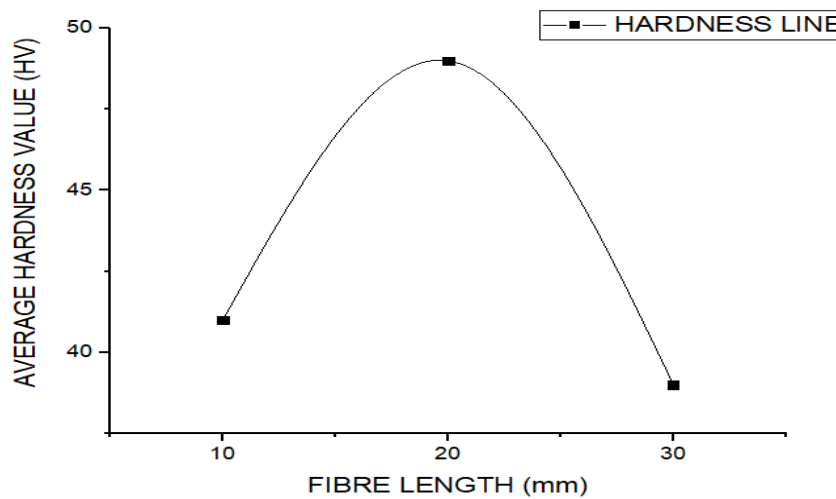

Figure 13 Average hardness values of hybrid composites

\section{E. Morphological Analysis}

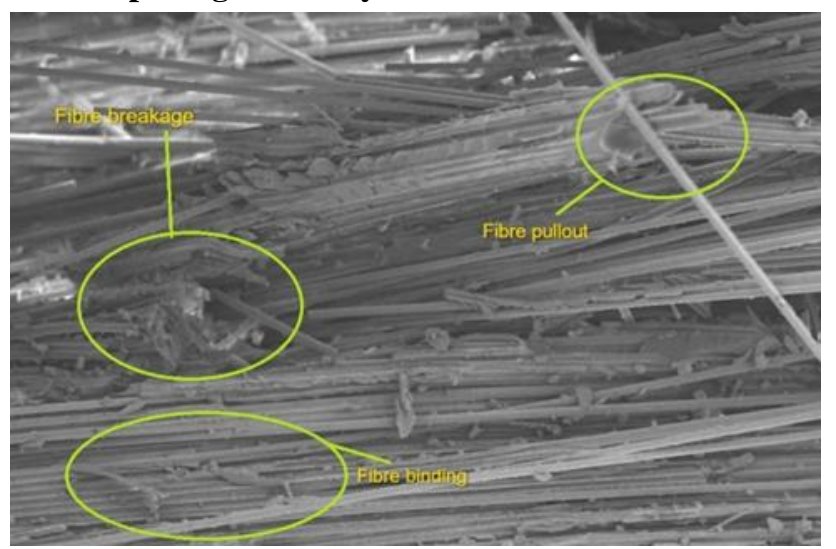

Figure 14 a) SEM image of fiber breakage, fiber pull out and fiber binding of flexural specimen

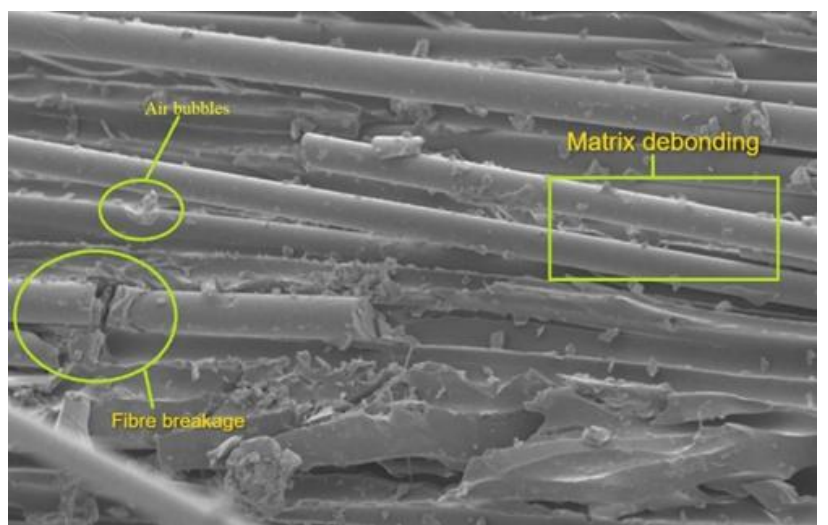

Figure 14. b) SEM image of air bubbles, fiber breakage and matrix debonding of flexural specimen

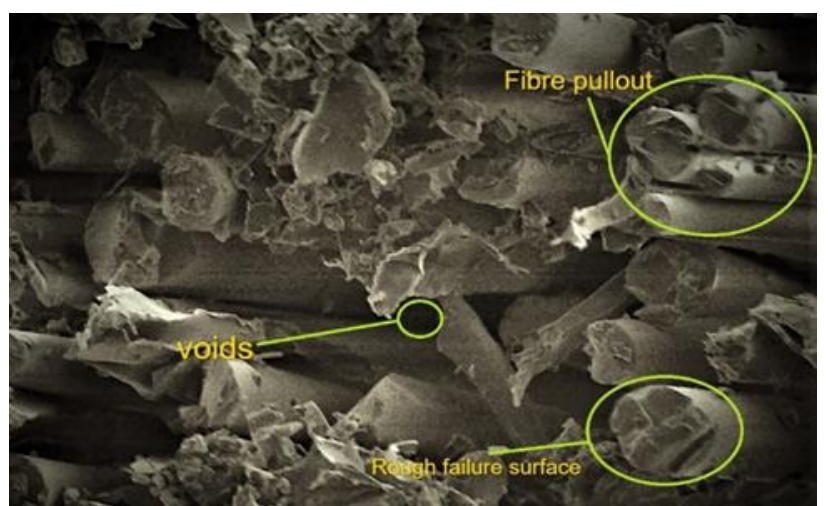

Figure 15 a) SEM image of fiber pull out, voids and rough failure surface of tensile specimen

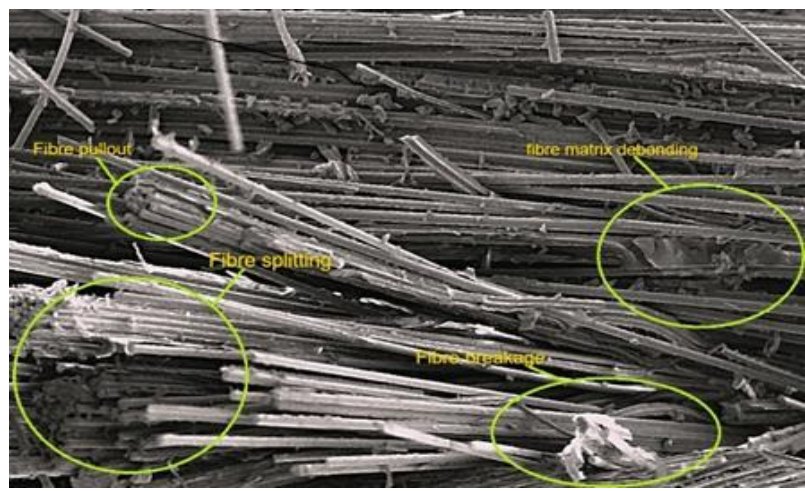

Figure 15.b) SEM image of air bubbles, fiber breakage and matrix debonding of flexural specimen

The morphological analysis of coir-jute hybrid composites was studied using scanning electron microscope after conducting mechanical testing. The figure 14 clearly explains the fiber-matrix interfacial failure on flexural tested specimen. In figure 14 (a) fiber pull out, fiber binding and fiber breakage was evidently noticed on $50 \mu \mathrm{m}$ which has good physical bonding with fiber and matrix at fiber binding zone and flexural tested fiber breakage zone are also noticed. In figure 14 (b) there are few defects on the flexural testing like air bubbles, fiber breakage and matrix debonding which reduces the strength of the composite slightly.

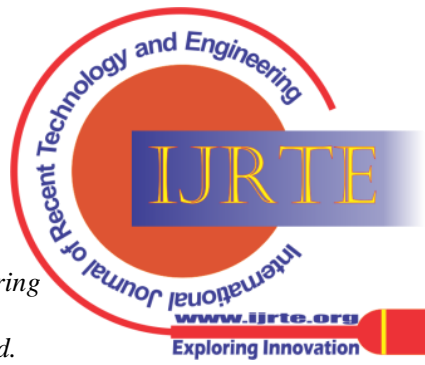
and Sciences Publication

(C) Copyright: All rights reserved. 
Even though the fabrication of the jute-coir hybrid composite of different fiber size was done with care, it seen that intra fiber delamination present in the fibers which reduces the strength of the composite. In Figure 15 (a), (b) shows the tensile tested specimen were the loading of the tensile test was done on horizontal direction, so the damage will be more along the same direction. Due to the high strength of the coir fiber it undergoes individual breakage gives it very high strength with all composites. But $20 \mathrm{~mm}$ fiber size hybrid composite withstands more strength than other composites as shown in figure 14 (b). Along with these the rough failure surface and void of the fiber bonded with matrix undergoing tensile tested specimen are shown in figure 14 (a) respectively.

\section{F. Anova Analysis}

The statistical analysis has been carried by the one way analysis of variance (ANOVA) on three different size of fiber length hybrid composites was executed with flexural and tensile strength data.[32] ANOVA analysis was delivered in table 6 and 7 decays the variance of flexural and tensile strength into two apparatuses; a within group (WG) and a between group (BG) respectively. The F-ratio of the tensile strength and flexural strength on the ANOVA analysis was 10.40 and 25.65 obtained. There is a statistically difference between the average value of tensile strength and flexural strength from one level of fiber length hybrid composite to another combination at the 95\% confidence level. The test result denotes $\mathrm{P}$-value of the F-test for both the result is less than $5 \%$.

\begin{tabular}{|c|l|c|c|c|}
\hline S.NO. & $\begin{array}{l}\text { SOURCE OF } \\
\text { VARIATION }\end{array}$ & $\begin{array}{c}\text { DEGREES } \\
\text { OF } \\
\text { FREEDOM }\end{array}$ & $\begin{array}{c}\text { MEAN } \\
\text { SQUARE }\end{array}$ & F-RATIO \\
\hline 1. & $\begin{array}{l}\text { BETWEEN } \\
\text { SPECIMENS }\end{array}$ & SSC=79.83 & 2 & F $_{\mathrm{C}=\mathrm{MSC} / \mathrm{MSE}=10.40}$ \\
\hline 2. & $\begin{array}{l}\text { WITH IN } \\
\text { SPECIMENS }\end{array}$ & SSE=23.01 & 6 & \\
\hline
\end{tabular}

Table 6 Anova test for tensile strength of jute/coir reinforced unsaturated polyester resin hybrids and jute composites

ANOVA: analysis of variance; BG: between group; WG: within group; DF: degree of freedom; MS: mean square; and F: F-test for ANOVA.

Number of observations $=9$.

Number of samples $=3$.

$\mathrm{F}_{\mathrm{C}}=10.40$

$\mathrm{F}_{\mathrm{T}}=\mathrm{F}_{2,3}=9.55$

$\mathrm{FC}>\mathrm{FT}$

(There is a significant difference at $5 \%$ level of significance. The two readings are in differ in its results. So it rejects the null hypothesis)

\begin{tabular}{|c|c|c|c|c|}
\hline S.NO & $\begin{array}{l}\text { SOURCE OF } \\
\text { VARIATION }\end{array}$ & $\begin{array}{c}\text { MEAN } \\
\text { SQUARE }\end{array}$ & $\begin{array}{c}\text { DEGREES } \\
\text { OF } \\
\text { FREEDO } \\
\text { M }\end{array}$ & F-RATIO \\
\hline 1. & $\begin{array}{l}\text { BETWEEN } \\
\text { SAMPLES }\end{array}$ & $\begin{array}{c}\mathrm{SSC}=217 \\
2\end{array}$ & 2 & $\begin{array}{c}\mathrm{F}_{\mathrm{C}=\mathrm{MSC} / \mathrm{MSE}=25.6} \\
5\end{array}$ \\
\hline 2. & $\begin{array}{l}\text { WITH IN } \\
\text { SAMPLES }\end{array}$ & $\mathrm{SSE}=127$ & 6 & \\
\hline
\end{tabular}

Table 7 Anova test for flexural strength of jute/coir reinforced unsaturated polyester resin hybrids and jute composites

ANOVA: analysis of variance; BG: between group; WG: within group; DF: degree of freedom; MS: mean square; and F: F-test for ANOVA.

Number of observations $=9$.

Number of samples $=3$.

$\mathrm{F}_{\mathrm{C}}=25.65$

$\mathrm{F}_{\mathrm{T}}=\mathrm{F}_{2,3}=9.55$

$\mathrm{FC}>\mathrm{FT}$

(There is a significant difference at $5 \%$ level of significance. The two readings are in differ in its results. So it rejects the null hypothesis)

\section{CONCLUSION}

The present study deals with the potential ability of the development of natural fiber hybridization reinforced with matrix delivers improvement in various properties. Due to the hybridization of natural fiber with different fiber size the mechanical properties will increases, at certain stage increasing of fiber size the mechanical properties will get decreases. Based on these aspects the three different size of fiber size are chosen for this study. The fabrication of jute/coir hybrid composite as reinforcement of different fiber size with unsaturated polyester resin as matrix using compression moulding technique various mechanical testing are performed as per ASTM standards.

$>\quad$ The coir-jute hybrid fiber composites of $20 \mathrm{~mm}$ fiber size have more tensile strength than other fiber size can withstand the tensile strength of 23Mpa followed by the $10 \mathrm{~mm}$ fiber size and $30 \mathrm{~mm}$ fiber size composites which holds the value of $22.5 \mathrm{Mpa}$ and $15 \mathrm{Mpa}$ and which shows high improvement of $1 \%$ and $23 \%$ than other fiber size hybrid composites.

$>\quad$ The maximum flexural strength of coir-jute hybrid composites are delivered by $20 \mathrm{~mm}$ fiber size of $57.25 \mathrm{Mpa}$ followed by $10 \mathrm{~mm}$ and $30 \mathrm{~mm}$ fiber size composites which holds the value of $10.8 \mathrm{Mpa}$ and 33Mpa respectively. And it shows much improvement of $32.41 \%$ and $10.6 \%$ than other fiber size hybrid composites.

$>\quad$ There is trivial improvement in the impact strength of jute-coir hybrid composites of $20 \mathrm{~mm}$ fiber size of $15.3 \mathrm{~J}$ followed by $10 \mathrm{~mm}$ and $30 \mathrm{~mm}$ fiber size composites which holds the value of $10.5 \mathrm{~J}$ and $11.7 \mathrm{~J}$ respectively. Also, it has high improvement of $12.8 \%$ and $9.6 \%$ than other combinations.

> The micro hardness analysis obtained in $20 \mathrm{~mm}$ fiber length of coir-jute hybrid composite of $49 \mathrm{H} 2 \mathrm{v}$ as compared with other combinations it has high improvement of $6.28 \%$ and $7.75 \%$ correspondingly.

$>$ Along with these mechanical studies the failure morphological studies of flexural and tensile tested specimens were examined. Laterally one way ANOVA analysis was also examined the significant differences of test results obtained from different fiber size composites.

Blue Eyes Intelligence Engineering and Sciences Publication 


\section{Fabrication and Mechanical Characterization of Jute-Coir Reinforced Unsaturated Polyester Resin Hybrid Composites with Various Fiber Size using Compression Moulding Technique}

A conclusion section is not required. Although a conclusion may review the main points of the paper, do not replicate the abstract as the conclusion.

$>$ A conclusion might elaborate on the importance of the work or suggest applications and extensions.

\section{REFERENCES}

1. Susilendra mutalikdesai, "mechanical characterization of mmt nano clay/epoxy/ basalt fiber composites" materials science and engineering, 1065 (2021) 012026.

2. Abdul nazeer, "to study the mechanical properties of coconut coir fiber reinforced with epoxy resin aw $106 \&$ hv 953 in" international journal of modern engineering research.

3. Vijay b r, "mechanical characterization of coir fiber reinforced epoxy composites with and without tio2 filler" international journal of engineering research \& technology, issn: 2278-0181, vol. 5 issue 01, january-2016.

4. Anand kumar mehra, "synthesis and analysis of mechanical Properties of luffa cylindrica and coconut coir reinforced epoxy composite" international journal of innovative research in science, engineering and technology, vol. 8, issue 10, october 2019.

5. Deepak singh rathore, "experimental analysis of mechanical properties of coconut coir fiber \& wheat straw composite material" international journal of engineering sciences \& research technology, issn: 2277-9655, 8(5): may, 2019.

6. Satender kumar, "mechanical properties of coconut fiber reinforced epoxy polymer composites" international research journal of engineering and technology, volume: 03 issue: 07 | july-2016.

7. Fernanda santos da luz, "ballistic application of coir fiber reinforced epoxy composite in multilayered armor" materials research. 2017; 20(suppl. 2): 23-28.

8. Greeshma gireesan, "study of mechanical behavior of coir reinforced epoxy composite" international journal of advanced research in management, architecture, technology and engineering, vol. 3, issue 4, april 2017

9. Sivasaravanan.s, "impact characterization of epoxy ly556/e-glass fibre/ nano clay hybrid nano composite materials" 12th global congress on manufacturing and management, gcmm 2014, 97 ( 2014 ) $968-974$.

10. Chizoba obele, "mechanical properties of coir fiber reinforced epoxy resin composites for helmet shell" industrial engineering letters, issn 2224-6096 (paper) issn 2225-0581 (online), vol.5, no.7, 2015.

11. Debasmita pani, "analysis of mechanical properties of coir composites with varied compositionsanalysis of mechanical properties of coir composites with varied compositions" international journal of material sciences and technology. Issn 2249-3077 volume 9, number 1 (2019), pp. 1-12.

12. Yadvinder singh, "fabrication and characterization of coir/carbon fiber reinforced epoxy based hybrid composite for helmet shells and sports-good applications: influence of fiber surface modifications on the mechanical, thermal and morphological properties" j o u r $\mathrm{n}$ a 1 of ma t e ri a ls re s e arch and technology 2020 ; 9 (6) ): 15593 - 1 5603 .

13. U. Sundara vinayaka, "experimental study of mechanical properties of epoxy resin nanoclay composites" international journal of latest engineering research and applications, issn: 2455-7137, volume - 02, issue - 04, april - 2017, pp - 180-186.

14. Kavin kumar k, "mechanical characterisation of glass/epoxy, carbon/epoxy and hybrid composite" ijcrt | volume 5, issue 4 november 2017 | issn: 2320-2882.

15. Adewale george adeniyi, "a review of coir fiber reinforced polymer composites" composites part b 176 (2019) 107305.

16. Júlio c. Dos santos, "eco-friendly sodium bicarbonate treatment and its effect on epoxy and polyester coir fibre composites" construction and building materials 211 (2019) 427-436.

17. Libo yan, "effect of alkali treatment on microstructure and mechanical properties of coir fibres, coir fibre reinforced-polymer composites and reinforced-cementitious composites" construction and building materials 112 (2016) 168-182.

18. Libo yan, "effect of water, seawater and alkaline solution ageing on mechanical properties of flax fabric/epoxy composites used for civil engineering applications" construction and building materials 99 (2015) 118-127.
19. Majid ali, "experimental investigations on coconut-fibre rope tensile strength and pullout from coconut fibre reinforced concrete" construction and building materials 41 (2013) 681-690.

20. S.stephano, "fabrication of hybrid coconut fibre With epoxy composite" international journal of innovative works in engineering and technology, issn: 2455-5797.

21. A.k. Mohanty and m. Misra "studies of jute composites-a literature review" polymer-plastics technology and engineering volume 34 page 729-792 2006.

22. Adewale george, adeniyidamilola, victoriaonifade, joshua oighalo akorede, samsonadeoye "a review of coir fiber reinforced polymer composites” composties part-b: engineering volume 1762019.

23. S. Kalia, b. S. Kaith, and i. Kaur, "pretreatments of natural fibers and their application as reinforcing material in polymer composites a review" polymer engineering and science 2009.

24. Jiuming xie.et.al "process optimization for compression molding of carbon fiber-reinforced thermosetting" polymer materials volume 12 , 24302019

25. Astm d3039-8: standard test method for tensile properties of polymer matrix composite materials. Astm committee d30, los angeles, america, 2005.

26. Aofeiguoa, zhihuisunb, jagannadh, satyavolu "experimental and finite element analysis on flexural behavior of mortar beams with chemically modified kenaf fibers" construction and building materials volume 292 july 2021.

27. Ruey shan, chenyusri, helmimuhammad, sahrimahmad "physical, mechanical and environmental stress cracking characteristics of epoxy/glass fiber composites: effect of matrix/fiber modification and fiber loading" polymer testing volume 962021

28. Abhishek t.h.m., g.k.mrutyunjaya gouda, "evaluation of mechanical and water absorption behaviour of coir and rice husk reinforced composites" international journal of research in engineering and technology volume: 05 issue: 03 mar-2016

29. Maria ernestina, alves fidelisa, thatiana vitorino, castropereira et.al "the effect of fiber morphology on the tensile strength of natural fibers" journal of materials research and technology volume 2, issue 2, april-june 2013, pages 149-157.

30. Reeghanosmond, zahramollahoseini, jeevanjotsingh, abhisargautam, rudolfseethaler, kevingolovin, abbas s.milani "a group multicriteria decision making with anova to select optimum parameters of drilling flax fibre composites: a case study" composites part-c: open access may 2021.

31. A. F. Ab ghani, m.y yaakob, m.n. Salim, j mahmud "hardness assessment of hybrid composite cfrp and gfrp" international journal of recent technology and engineering issn: 2277-3878, volume-8, issue-1s5, june 2019.

32. r.s.teixeiraa, s.f.santosb, a.l.christoforoc, j.payád, h.savastano, f.a. Roccolahr "impact of content and length of curauá fibers on mechanical behavior of extruded cementitious composites: analysis of variance" cement and concrete composites volume 1022019.

33. M. Abeens, e. Rajasekaran, m. Premnath, d. Sarukasan, r. Muruganandhan, k. Thirumavalavan "experimental and numerical investigation of residual stresses in low pulsed laser shock peening on aa7075 t651" iop conf. Series: materials science and engineering, volume 1126, 2021.

\section{AUTHORS PROFILE}

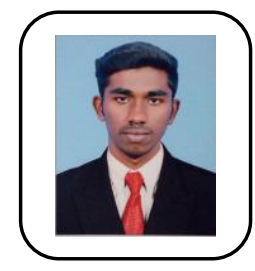

Mr. D. Sarukasan, Research Scholar in Department of Mechanical Engineering, College of Engineering Guindy, Anna University, Chennai, Tamil Nadu, India. In his duration of continuous study from B.E Mechanical Engineering, M.E Energy Engineering follow with pursuing Ph.D. in Anna University Chennai employed under research in composites for Energy saving applications.

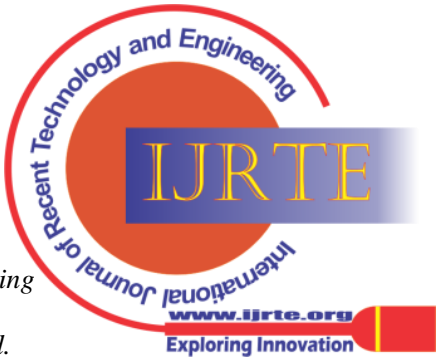




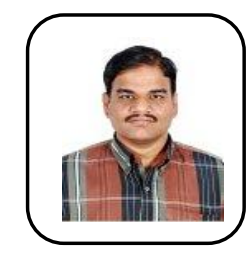

Dr. K. Thirumavalavan, Assistant Professor (Selection Grade) Department of Mechanical Engineering, College of Engineering Guindy, Anna University, Chennai, Tamil Nadu, India. He has more than 20 years of teaching and research experience, works under various project in the field of Material Characterization, surface tropology and severe Plastics Deformation.

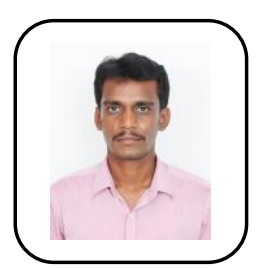

Mr. Prahadeeswaran M, Research Scholar in Department of Industrial Engineering, College of Engineering Guindy, Anna University, Chennai, Tamil Nadu, India. In his duration of continuous study from B.E Mechanical Engineering, M.E Manufacturing Engineering follow with pursuing Ph.D. in Anna University Chennai employed under research in composites for Energy saving applications. Worked as Assistant Professor in Mechanical Engineering in MAHER, Chennai.

Dr. R.Muruganandhan, Working as an Associate Professor in Department of Mechanical Engineering at College of Engineering, Guindy, has completed a Doctorate Degree in Composite Materials from Faculty of Mechanical Engineering, College of Engineering, Guindy, Anna University and also published 13 papers in UGC approved journals

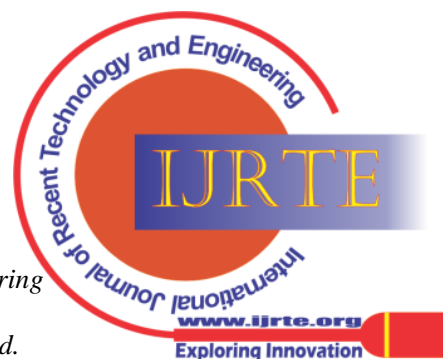

